BNWL-SA-4984

CONf-740511-.5

\title{
SOUSA: A Root Finder for Nonlinear Equations
}

\author{
Keywords and Phrases: root finder, nonlinear equation solver, \\ bisection method, roots, zeros.
}

by

C. A. Oster

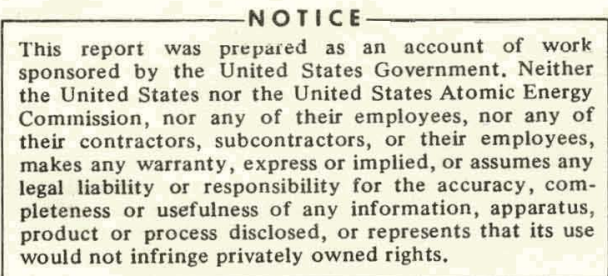

product or process disclosed, or represen
would not infringe privately owned rights.

BATTELLE

Pacific Northwest Laboratories

Richland, Washington 99352 


\section{DISCLAIMER}

This report was prepared as an account of work sponsored by an agency of the United States Government. Neither the United States Government nor any agency Thereof, nor any of their employees, makes any warranty, express or implied, or assumes any legal liability or responsibility for the accuracy, completeness, or usefulness of any information, apparatus, product, or process disclosed, or represents that its use would not infringe privately owned rights. Reference herein to any specific commercial product, process, or service by trade name, trademark, manufacturer, or otherwise does not necessarily constitute or imply its endorsement, recommendation, or favoring by the United States Government or any agency thereof. The views and opinions of authors expressed herein do not necessarily state or reflect those of the United States Government or any agency thereof. 


\section{DISCLAIMER}

Portions of this document may be illegible in electronic image products. Images are produced from the best available original document. 
SQUSA: A Root Finder for Nonlinear Equations

$$
\begin{gathered}
\text { C. A. Oster } \\
\text { BATTELLE } \\
\text { Pacific Northwest Laboratories }
\end{gathered}
$$$$
\text { Richland, Washington } 99352
$$

\section{ABSTRACT}

A marching search and bisection procedure for solving under rather general conditions, the nonlinear equation $f(x)=0$ is presented. The algorithm design and operating characteristics are discussed. Results of applying this procedure to a set of test functions are given. Finally the Fortran coding of the procedure is included.

Keywords and Phrases: root finder, nonlinear equation solver, bisection method, roots, zeros. 


\section{IIITRODUCTION}

A great amount of scientific computing activity deals with solving equations, i.e. finding roots of functions. Procedures abound for solving equations. No single method is universally optimal. Here optimality must be defined in such terms as function complexity, number of times the solution must be obtained, deadlines, and computing costs. There seems to be a time and place for each method. Rice[1] has combined several methods into one procedure in an attempt to obtain a good practical root finding package. Here we present a rather simple procedure which can be used with little effort when conditions do not justify a more sophisticated procedure. 
The marching search and bisection procedure is a relatively foolproof process for locating the real zeros of functions. By properly constructing the algorithm one may also use it to isolate extrena, or odd order poles of a function under rather general conditions. It can also be used to solve systems of equations. This will be discussed more below.

One might question the use of such a brute force attack when elegant' procedures such as Newton's method or its relatives are avaitable. To answer this question first note that the program described herein is not a panacea, for example one would normally not use it to solve one linear. equation or even to extract square roots. Following is a list of reasons and circumstances where this procedure is applicable.

1. The function may be too difficult to differentiate.

2. The function is quite flat i.e. the derivative is nearly zero or if a system of functions is being considered the Jacobian is nearly singular.

3. The job at hand is a "one-shot" application and the time (cost) does not permit an in-depth analysis of the functions.

4. The user may be relatively ignorant of numerical methods and has no desire to devote the time and energy to learning them.

5. This procedure can be used to drive the error to the computational limits (noise level) where other methods fail.

Two highly desirable characteristics for any root finding algorithm are also present in SOUSA. These are

1. An error bound can be readily obtained.

2. Roots of arbitrary order presenl no difficultics. 
The algorithm given here is not without its shortcomings however. Most have been identified and should the user encounter such he will be dually notified. The identified pitfalls are discussed at length below.

Once a root has been bracketed the algorithm becomes a simple bisection process which is known to have a convergence factor of $1 / 2$. That is the interval containing the root is halved with each step.

\section{APPLICATION TO A SYSTEM OF EQUATIONS}

The algorithm has been implemented as a FORTRAN subroutine named SOUSA which is listed in Appendix $B$. The reverse communication technique has been employed to aid the user. By including two or three simple statements the user may have a root finder in place. Explicit details for calling this subprogram will be discussed later. For now consider the solution of a system of equations without much of this detail. Figure 1 indicates how the two nonlinear equations

$$
\begin{aligned}
& f(x, y)=y-x^{2}+y^{2} \\
& g(x, y)=x-x^{2}-y^{2} .
\end{aligned}
$$

can be solved using SOUSA. The extension to higher dimensioned systems is straight forward.

This block has been simplified somewhat since KEY carries other information which can be usefur and which has not been needed here. The first two blocks show the initialization essentials. Once the starting point $(x, y)$; step sizes $\Delta x, \Delta y$; convergence criteria $\varepsilon x, \varepsilon y$; and logic switchs KEYX, KEYY are given the solution loops follow. First the equation $f(x, y)=0$ is solved for $x$ while keeping $y$ fixed. When $x$ has been refined so as to pass the convergence criteria (This test is made in SOUSA where KEYX is set to 1 if the test is not passed.), the solution moves on 
Initialize

$x$, : Eutimate of $A$

$\%:$ Extinate of $t$

$h_{1}: 0<\ln <1$

$E$ : Comarance factor

$E_{0}$ : Crude Combizance factor

$x^{*}+x_{0}, y^{*}+y_{0}$

$x+x_{0}, y \approx y_{0}$

$\Delta x+x_{0} / 10 ; \quad \Delta y+y_{0} / r 0$

KEYX - $0, \quad K E Y Y \propto 0 \ldots$

$\epsilon_{x} \approx \epsilon_{s}$

$\epsilon_{y^{-}} \epsilon_{0}$

$\Delta x+x-x^{*}, \quad \Delta y+y-y^{*}$

$x^{*} 4 x \quad y^{*}+y$

KEYX -3 KEYY -3

$\epsilon_{x}-\max \left(h \epsilon_{x}, \epsilon\right), \epsilon_{j}-\max \left(h \epsilon_{y}, \epsilon\right)$

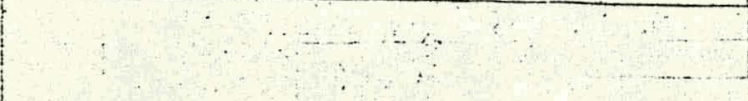
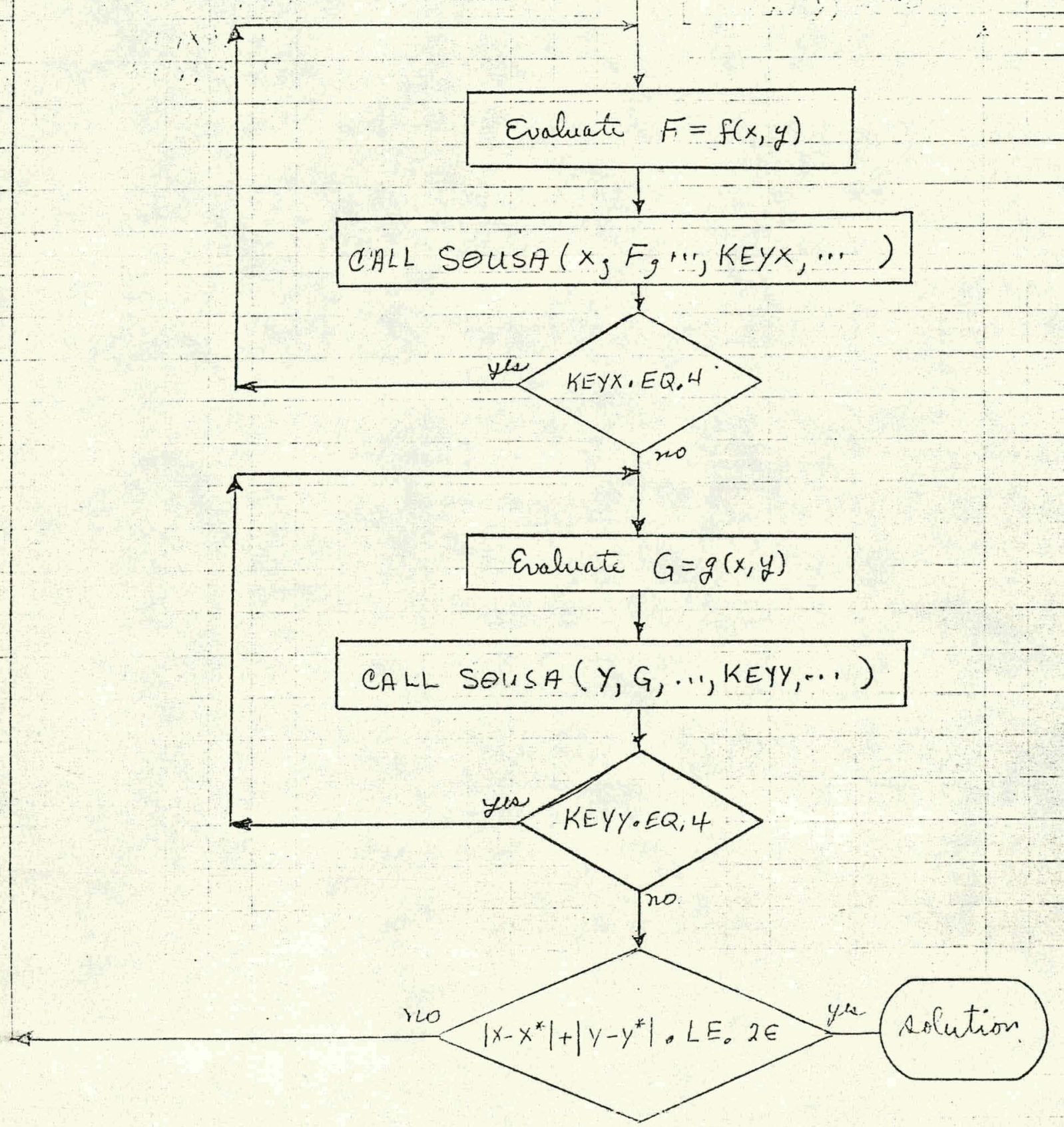

Figure 1. Flow Chart Showing the Use of SOUSA to Solve Two Equations in Two Unknowns. 
to the second equation $g(x, y)=0$. Then while keeping $x$ fixed, $y$ is determined in a manner similar to that used for $x$. If the new point $(x, y)$ is sufficiently close to the starting point $\left(x^{*}, y^{*}\right)$ the solution is assumed to be $(x, y)$, Otherwise the point $(x, y)$ becomes the new starting point, the convergence criteria are sharpened if necessary, and the procedure repeated.

This procedure was programmed. Taking $\varepsilon_{0}=10^{-3}, h=0.5$, $\varepsilon=10^{-7}$ and starting from $\left(x_{0}, y_{0}\right)=(0.8,0.4)$ the nontrivial solution (0.77184452, 0.41964338) was obtained. Initially about 22 evaluations for each function was needed to solve the individual equations. At the end of the process only 4 evaluations were required for each equation. In all a total of 673 and 682 evaluations of $f$ and $g$ respectively were required. 
DISCUSSION

Now let us turn to additional information provided by the subroutine SOUSA. What other information can be obtained? Figures 2 and 3 are representative of the possible situations which might be encountered during a search of a function for zero. Figure 2 a denotes the class of functions which have zeros in an interval, the slope might be negative, and/or curvature negative etc. Similarly d. might well be the negative of the function shown.

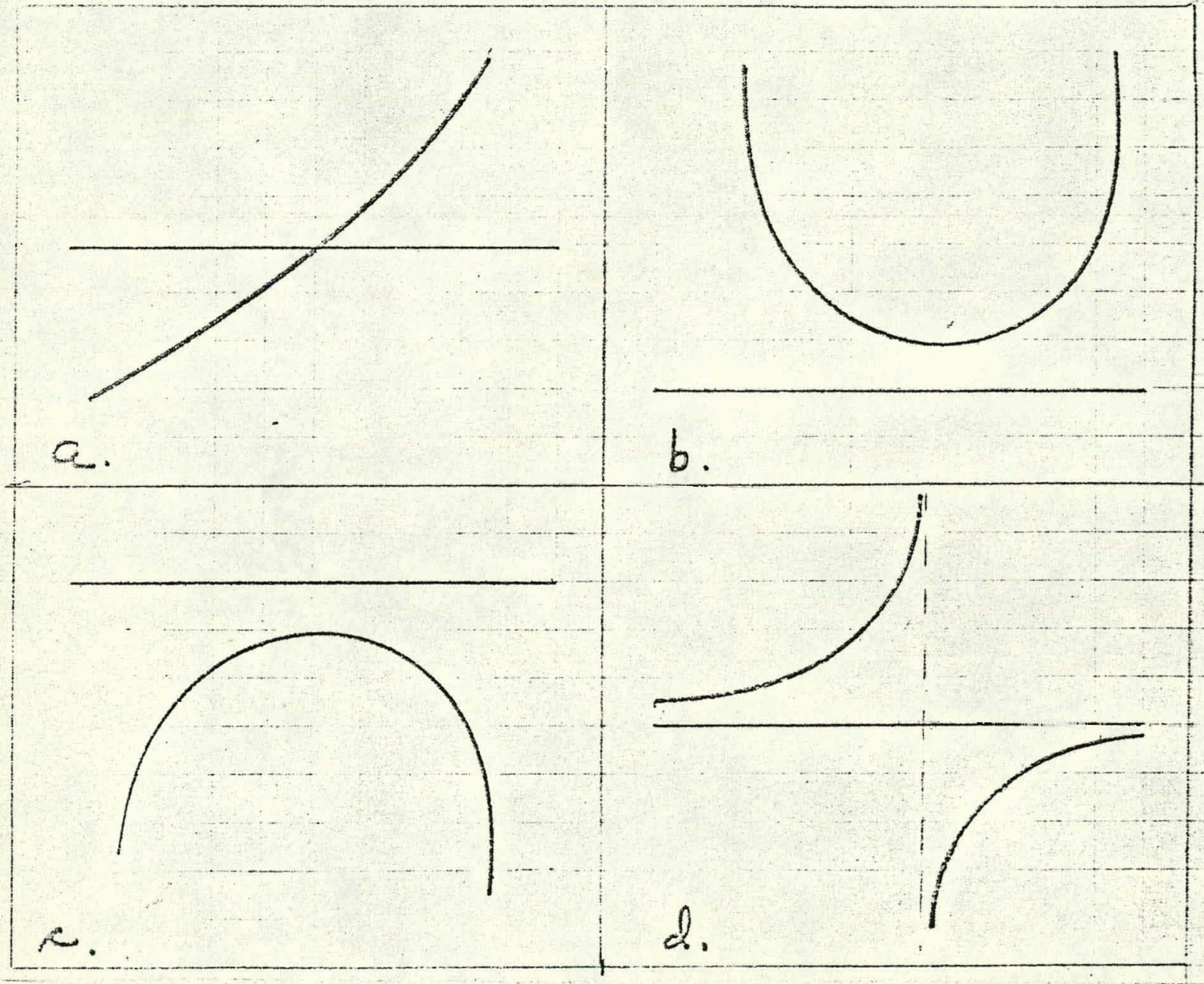

FIGURE 2. Potential Function Shapes Which Stop the Search 
The procedure is stopped when any one of the shapes shown in Figure 2 is encountered. Case a. represents the class of primary target functions for which the routine was designed. The other cases might be considered nuisances, however, SOUSA will yield the locations of extrema or odd order poles too.

Figure 3 depicts situations where the procedure output is of questionable value.

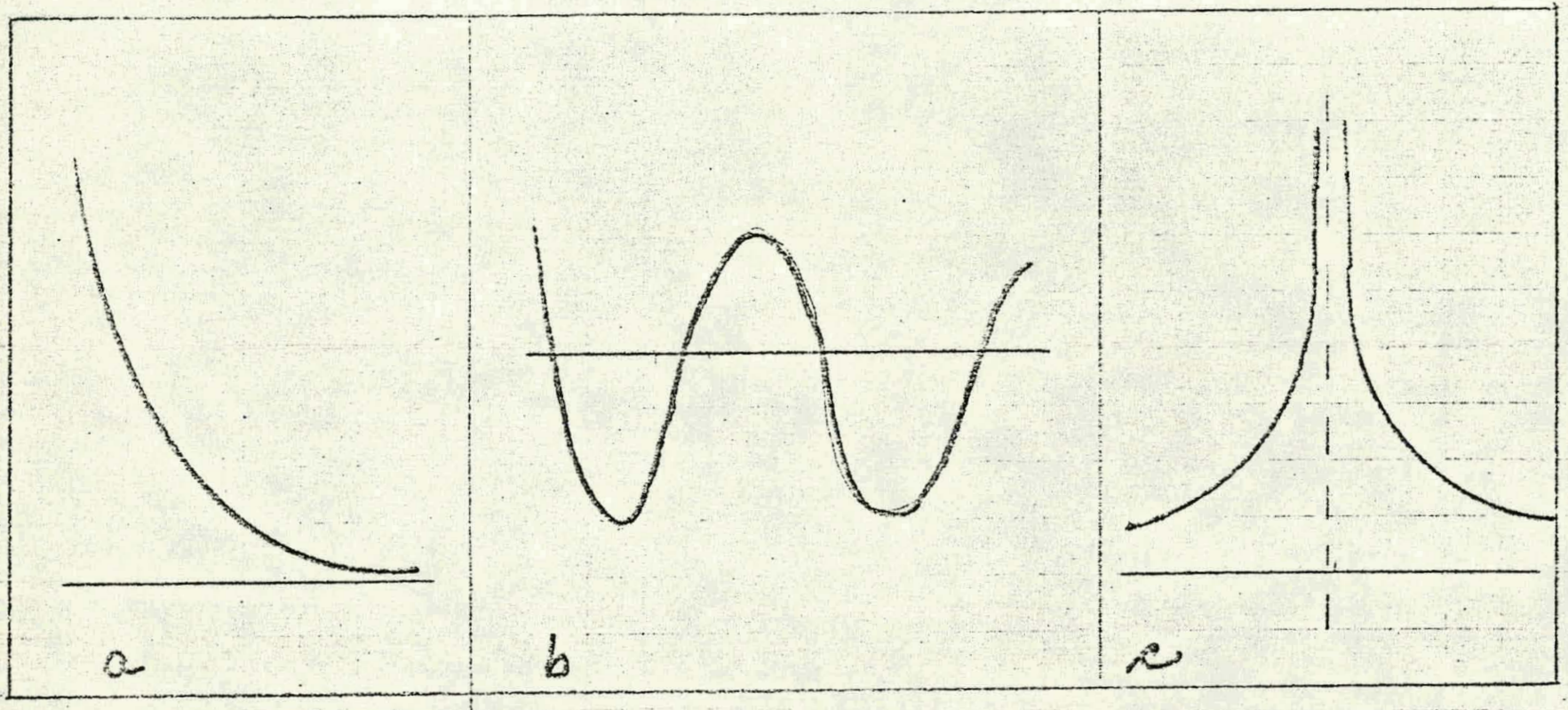

FIGURE 3. Function Shapes which Cause the Procedure to Fail

Figure $3 a$ has no zero. The program given here permits one to double the step size at regular intervals thereby covering the range more quickly. Figure 3b has zeros but the step size might not permit detection of them. If this occurs the algorithm believes it has case $3 a$ again. For example, suppose $f(x)=$ $\sin x$ and $\Delta x=2 \pi$. Unless round-off and truncation error save the march it will be fruitless! Case 3b will generaliy yield one of the zeros after suitably changing the step size. The other zeros are not located. 
Case $3 c$ is seen by the algorithm as a special case of $3 a$. That is, the march simply moves away from the pole in a direction depending upon the starting point and step sign and magnitude.

The algorithm programmed here correctly identifies each case in Figure 2. Those in Figure 3 are identified as "not successful". The user may then wish to take further action. For example, a different starting point and/or step size might be successful in case $3 b$. Cases $3 a$ and $3 c$ have no zeros so obviously the user cannot expect to find one.

During the marching search the general strategy is to move toward the origin if possible. The decisions underlying this strategy are tabulated in Table 1. More information is required than shown in Table 1 to properly implement the search. For example, conditions 1 and 2 can be repeated cyclicly to produce a three step loop. Similarly, conditions 5 and 6 might produce a loop. When these conditions occur, preventative action is called for. If two consecutive sign changes of $\Delta x$ occur, then $\Delta x$ is halved and the search continued. This strategy leads to the determination of local extrema such as shown in Figure $2 b$ and $2 c$.

Once the root has been bracketed the strategy is determined from Table 2. At each step a and $b$ are the end points of the interval containing the root giving an estimate of the error. The eight entries of Table 2 are readily implemented in Fortran by an assigned $\mathrm{G} \theta$ T $\theta$ statement with index constructed as follows. Assign a binary digit to each of columns 2, 3 and 4 . Associate column 2 with the 4 digit, column 3 with the 2 digit and column 4 with the 1 digit. Now set each digit 1 if the corresponding key is positive and 0 if the key is negative. The resulting integer is increased by 1 to obtain the GO TO index ranging between 1 and 8 inclusively. 
TABLE 1. Decision Table Used for Marching Search

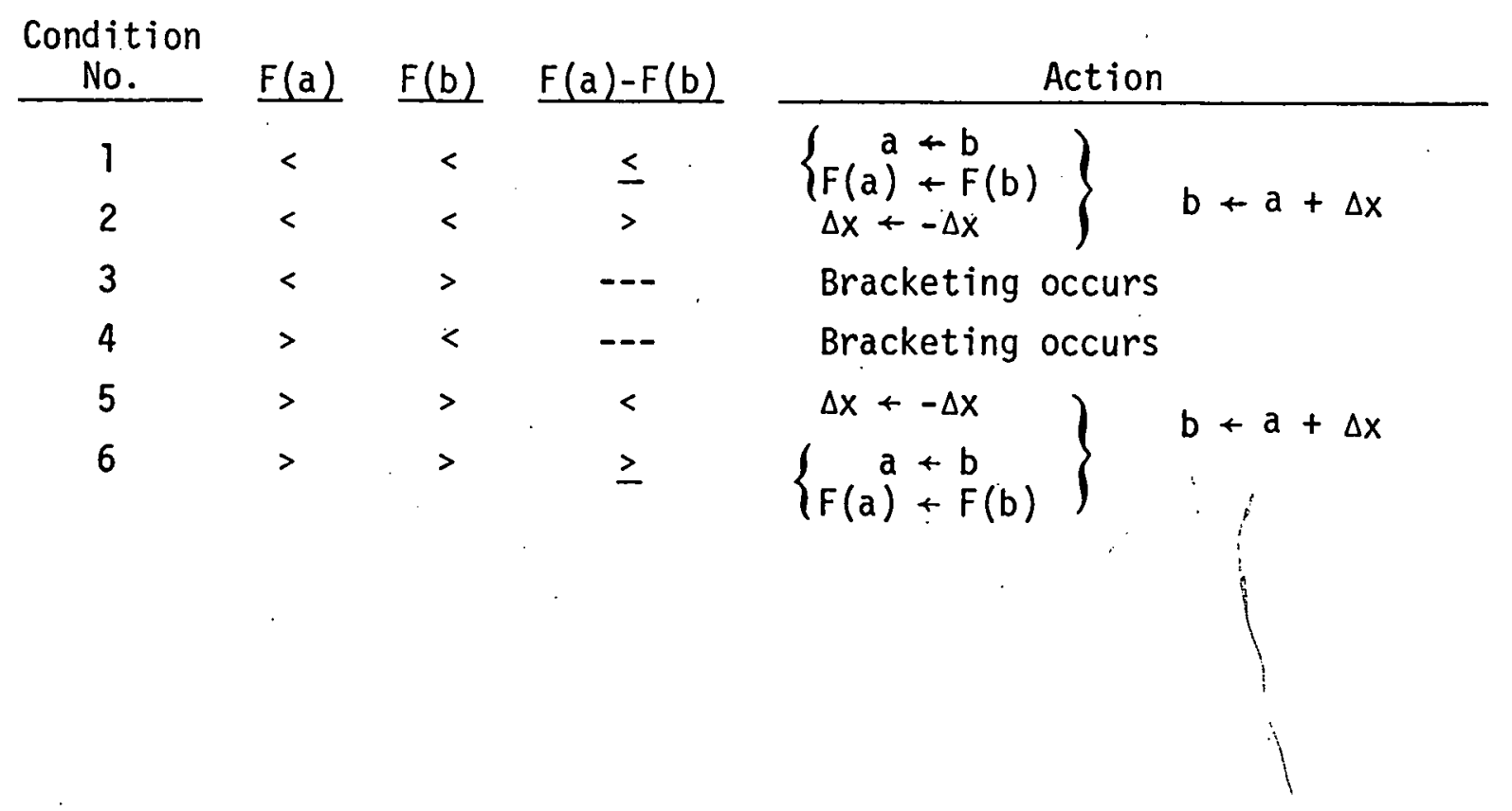

TABLE 2. Decision Table When Root Lies Between $a$ and $b$

\begin{tabular}{|c|c|c|c|c|c|}
\hline $\begin{array}{c}\text { Condition } \\
\text { No. }\end{array}$ & $(f(b)-f(a)) * \Delta x$ & $\underline{\Delta x}$ & $\underline{f(y)}$ & Action & \\
\hline 1 & $<$ & $<$ & $<$ & $a+y \quad$ & \\
\hline 2 & $<$ & $<$ & $>$ & $b \leftarrow y$ & \\
\hline 3 & $<$ & $>$ & $<$ & $b \leftarrow y$ & Followed by \\
\hline 4 & $<$ & $>$ & $>$ & $a \leftarrow y$ & $\Delta x \leftarrow \Delta x / 2$ \\
\hline 5 & $>$ & $<$ & $<$ & $b \leftarrow y$ & $y+a+\Delta x$ \\
\hline 6 & $>$ & $<$ & $>$ & $a+y$ & \\
\hline 7 & $>$ & $>$ & $<$ & $a+y$ & \\
\hline 8 & $>$ & $>$ & $>$ & $b \leftarrow y$ & \\
\hline
\end{tabular}


In contrast to Table there is on ty one place where fajture may occur. Namely, $\Delta x$ can be reduced to the point that when added to a the result is unchanged. This is caused by the granularity of the number system used in digital computing. The only solution seems to be either accept the quantity $x$ as the solution or use it as a starting point in a double precision pursuit of the root. 
PROGRAM USE

The subroutine described here is called by the following FORTRAN

statement:

CALL SOUSA (X, FX, DX, KEY, MAXDBL, IMAX, EPSLN, FP, IP) where at the entry to SOUSA the arguments are given in the

Entry Table: $x$ is the approximate value of the sought root (or other characteristic) of the function $f(x)$.

FX is the value of $f(x)$ at the point $x$.

$D X$ is the initial step size $\Delta x$.

KEY is the type indicator. KEY must be less than or equal to -3 initially. It is reset by SOUSA and on output indicates the function's behavior according to the Return Table below.

MAXDBL is the number of consecutive steps permitted in one direction before the step size is doubled. If MAXDBL $\leq 0$ then it is replaced by 5 .

IMAX is the maximum of steps to be permitted during the search. EPSLN is the convergence criterion. The search is stopped when

(a) $f(x)=0$ or

(b) $x \neq 0$ and $|\triangle x / x| \leq$ EPSLN or

(c) $x=0$ and $\Delta x=0$ or

(d) $f(x) \neq 0$ and $|1 . / f(x)| \leq$ EPSLN.

See KEY in the Return Table below for the type of point $x$ is when the search is terminated.

FP is a REAL array dimensioned greater than or equal to 11. FP is used for intermediate storage. Some of the values stored in FP are discussed in the Return Table.

IP is an INTEGER array dimensioned greater than or equal to 5 . IP is used for intermediate storage. Some of the values of 
IP are'discussed below in the Return Table

At the time of returning from SOUSA to the calling program the argument in the call 7ist are given in the

Return Table:

$x$ is the new value of $x$ to be used to evaluate $f(x)$ for the next step if the search is continuing. 0therwise $X$ is the sought root.

Key is -2 if $f$ has an odd order pole very near $x$

-1 if $f(x)<0$ and $f(x)$ is a relative maximum

$f(x)=0$

1 if $f(x)>0$ and $f(x)$ is a relative minimum

2 the step size has been reduced to the point that when added to $x$ the value of $x$ remain unchanged.

3 if none of the above conditions hold and IMAX steps have been taken.

$F P(1)$ is the current step size

$F P(2)\}$ are end points of the interval containing the $F P(3)\}$ sought value of $x$.

Other call list arquments are used by the subprogram but are of little use to the user. The user is free to interrogate the two arrays FP and IP but he is warned against modifying the contents. To do so could lead to confusion and ultimately to disaster for the logic behind the search.

An estimate of the error involved in $x$ is given by the following inequality

$\min [F P(2), F P(3)] \leq x \leq \max [F P(2), F P(3)]$ 
Appendix A contains a brief performance profile for SOUSA. Test functions 1 through 11 are from Rice[2]. Examination of the results shown in this profile show that SOUSA may not correctly identify those roots where the function does not change sign in a small neighborhood of the root. For example the root at -157.2 in Function 4 is positive near -157.2 . Using $\varepsilon=10^{-7}$ SQUSA thought it had located a minimum, see Table A-2. However taking $\varepsilon=0$ produced the desired results as shown in Table A-3. 


\section{REFERENCES}

1. John R. Rice, "A polyalgorithm for the automatic solution of nonlinear equations," Proc. of 24th National Conference ACM Publication P-69, (1969), pp. 179-183.

2. John R. Rice, "A set of 74 Test Functions for Nonlinear Equation Solvers," Purdue University Computer Science Department Document No. CSD TR 34, April 1969. 


\section{Appendix A}

Table A-1. Test Functions

1. $f(x)=\cos (x)-x e^{x}$

2. $f(x)=(y+16) \log _{10}\left(1+y^{2}\right) \sqrt{|y-.8|}$

$$
y=x-1312
$$

3. $f(x)=(x-17)^{2}|x-17.1|^{1.8}(x-20)$

4. $f(x)=|x+157.2|^{1.5}|x-361.2|^{7}\left(x-10^{-6}\right) /\left|x-10^{-11}\right|$

5. $f(x)=\left(1+x^{2}\right) \operatorname{sgn}(\sin (x)) \quad|x|<10$

6. $f(x)=81-y(108-y(54-y(12-y)))=(3-y)^{4}$

$$
y=x-1.11111
$$

$f(x)= \begin{cases}1+x^{4} & |x|<10^{8} \\ 1.222 \times 10^{9}-|x| & |x| \geq 10^{8}\end{cases}$

8. $f(x)=20 / y^{15}+36 / y^{25}+40 / y^{35}+(475+1.12 / x) / y^{40}$

$$
\begin{aligned}
& -1.12 / x-4.5-6 / y^{4}-3 / y^{8} \\
& y=1+x
\end{aligned}
$$

9. $f(x)=x-m-e \sin (x)$

(a) $\mathrm{m}=.8, \mathrm{e}=.2$

(b) $\mathrm{m}=.8, \mathrm{e}=15$.

10. $\left\{\begin{array}{l}f(x, y)=y-x^{2}+y^{2} \\ g(x, y)=x-x^{2}-y^{2}\end{array}\right.$ 
Tables A-2 and A-3 were obtained using 48-bit mantissas for floating point numbers. The step size was doubled after every 5 consecutive steps made in the same direction. Table A-2 is associated with $\varepsilon=10^{-7}$ which demands approximately half the precision available. Table $A-3$ has $\varepsilon=0$ which demands full precision for convergence. 
Table A-2. Test Function Results with $\varepsilon=10^{-7}$

\begin{tabular}{|c|c|c|c|c|}
\hline $\begin{array}{l}\text { Function } \\
\text { No. } \\
\end{array}$ & $x_{0}$ & $\begin{array}{c}\text { Solution } \\
x\end{array}$ & $\begin{array}{c}\text { No. of } \\
\text { Evaluations }\end{array}$ & $\begin{array}{c}\text { Point Type } \\
\text { Identification }\end{array}$ \\
\hline 1 & $\begin{array}{l}0.5 \\
1.5\end{array}$ & $\begin{array}{l}0.51773737 \\
0.51773736\end{array}$ & $\begin{array}{l}21 \\
30\end{array}$ & $\begin{array}{l}\text { root } \\
\text { root }\end{array}$ \\
\hline 2 & $\begin{array}{l}1310 \\
1340 \\
1295\end{array}$ & $\begin{array}{l}1296.0001 \\
1295.9999 \\
1296.0000\end{array}$ & $\begin{array}{l}22 \\
22 \\
21\end{array}$ & $\begin{array}{l}\text { root } \\
\text { root } \\
\text { root }\end{array}$ \\
\hline 3 & $\begin{array}{l}15 \\
18 \\
22\end{array}$ & $\begin{array}{l}17.099998 \\
17.099999 \\
20.00000 !\end{array}$ & $\begin{array}{l}43 \\
44 \\
23\end{array}$ & $\begin{array}{l}\max \\
\max \\
\text { root }\end{array}$ \\
\hline 4 & $\begin{array}{r}-150 \\
150 \\
350\end{array}$ & $\begin{array}{l}-157.19998 \\
1.0000000 \times 10^{-6} \\
361.19996\end{array}$ & $\begin{array}{l}45 \\
58 \\
45\end{array}$ & $\begin{array}{l}\max \\
\text { root } \\
\text { root }\end{array}$ \\
\hline 5 & $\begin{array}{r}3 \\
-3\end{array}$ & $\begin{array}{l}3.1415929 \\
-3.1415929\end{array}$ & $\begin{array}{l}21 \\
21\end{array}$ & $\begin{array}{l}\text { root, } \\
\text { root }\end{array}$ \\
\hline 6 & 10 & $\begin{array}{l}1.8887695 \\
1.8895874\end{array}$ & $\begin{array}{l}26 \\
36\end{array}$ & $\begin{array}{l}\text { root } \\
\text { root }\end{array}$ \\
\hline 7 & $\begin{array}{l}-10^{10} \\
100 \\
10^{10}\end{array}$ & $\begin{array}{l}1.2220000 \times 10^{9} \\
0 \\
1.2220000 \times 10^{9}\end{array}$ & $\begin{array}{r}32 \\
203 \\
32\end{array}$ & $\begin{array}{l}\text { root } \\
\text { min } \\
\text { root }\end{array}$ \\
\hline 8 & $\begin{array}{l}-5 \\
-2 \\
-1.5 \\
-1.1 \\
-0.5 \\
0.5\end{array}$ & $\begin{array}{l}-4.3196499 \\
-2.0755178 \\
-2.0755178 \\
-2.0755177 \\
0.09799 .3976 \\
3.2985349 \times 10^{11}\end{array}$ & $\begin{array}{r}54 \\
21 \\
24 \\
28 \\
34 \\
203\end{array}$ & $\begin{array}{l}\max \\
\text { root } \\
\text { root } \\
\text { root } \\
\text { root } \\
\max \end{array}$ \\
\hline $\begin{array}{l}9(a) \\
(b)\end{array}$ & $\begin{array}{l}.8 \\
.8\end{array}$ & $\begin{array}{l}0.96433382 \\
-0.057176229\end{array}$ & $\begin{array}{l}22 \\
32\end{array}$ & $\begin{array}{l}\text { root } \\
\text { root }\end{array}$ \\
\hline $10\left\{\begin{array}{l}\dot{x}, f \\
y, g\end{array}\right.$ & $\begin{array}{l}.8 \\
.4\end{array}$ & $\begin{array}{l}0.77184452 \\
0.41964338\end{array}$ & $\begin{array}{l}673 \\
682\end{array}$ & $\begin{array}{l}\text { root } \\
\text { root }\end{array}$ \\
\hline
\end{tabular}


Table A-3. Test Function Results with $\varepsilon=0$.

\begin{tabular}{|c|c|c|c|c|}
\hline $\begin{array}{c}\text { Function } \\
\text { No. } \\
\end{array}$ & $x_{0}$ & $\begin{array}{l}\text { Solution } \\
\times \\
\end{array}$ & $\begin{array}{c}\text { No. of } \\
\text { Evaluations }\end{array}$ & Identification \\
\hline 3 & $\begin{array}{l}15 \\
18\end{array}$ & $\begin{array}{l}17.100000 \\
17.100000\end{array}$ & $\begin{array}{l}93 \\
88\end{array}$ & $\begin{array}{l}\text { root } \\
\text { root }\end{array}$ \\
\hline 4 & $\begin{array}{r}-150 \\
350\end{array}$ & $\begin{array}{l}157.20000 \\
361.20000\end{array}$ & $\begin{array}{l}90 \\
97\end{array}$ & $\begin{array}{l}\text { root } \\
\text { root }\end{array}$ \\
\hline
\end{tabular}


SUBRCUTINE SOUSA(X,FX,DX,KFY, MAXDBL, IMAX, EPSLN,FP, IP) DIMENSION FP(I.1), IP (5)

C-D THIS ROUTINE LOCATES THF POINT Y AT WHICH F IS AS CLOSE TO ZERO. AS POSSIBLE, OR WHERE F HAS AN ODD-ORDER POLE. A MARCHING TECHNIQUE IS USED TO BRACKET Y. ONCE Y HAS BEEN BRACKETEO, A BISECTION SEARCH IS CONDUCTED FOR ITS LCCFTION.

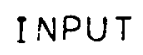

IMAX - MAXIMUM NUMBER OF STEPS TO BE TAKEN DURING THE SEARCH

EPSLN - CONVERGENCE CRITERION SOLUTION IS ASSUMED WHEN

IF $Y$-NE・ O THEN ABS $(D X / Y)$ - LE. EPSLN

IF $Y$.EQ. O THEN DX •EQ. $O$

A POLE IS ASSUMED WHEN F(Y) . NE • O AND ABS $: \triangle / F(Y)), L E$. FPSLN

FP - = LOATING POINT ARRAY USED FOR INTERMEDIATE STORAGE. MUST BE DIMENSIONED . GE. 11

IP - INTEGER ARRAY USED FOR INTERMEDIATE STORAGE. MUST BE DIMENSIONED . GE • 5 .

* *AUTION** FP AND IP MUST NOT BE MODIFIED BY THE CALL'ING PROGRAM DURING THE SEARCH.

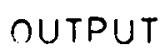

SOU0060

SOU0070

SOU 0080

SOU 0090

SOUO100

SกUO110

SOU0.120

SOUO 130

SOUO 140

SOUO150

SOUO160

SOU0170

SOUO180

SOUOI广O

SOU0 200

SOUO210

SOU0 220

SOUO 230

SOU0 240

SOUO 250

SOUO 260

SOUO 270

SOUO 280

SOUO 290

SOU0 300

SOU0 310

SOU0 320

SOU0 330

SOU0 340

SOU0 350

SOU0 360

SOU0 370

SOUO 380

SOU0 390

SOU0 400

SOU0 410

SOUO 420

SOUO 430

SOUO 440

SOU0 450

SOUO 460

SUU0 470

5040480 


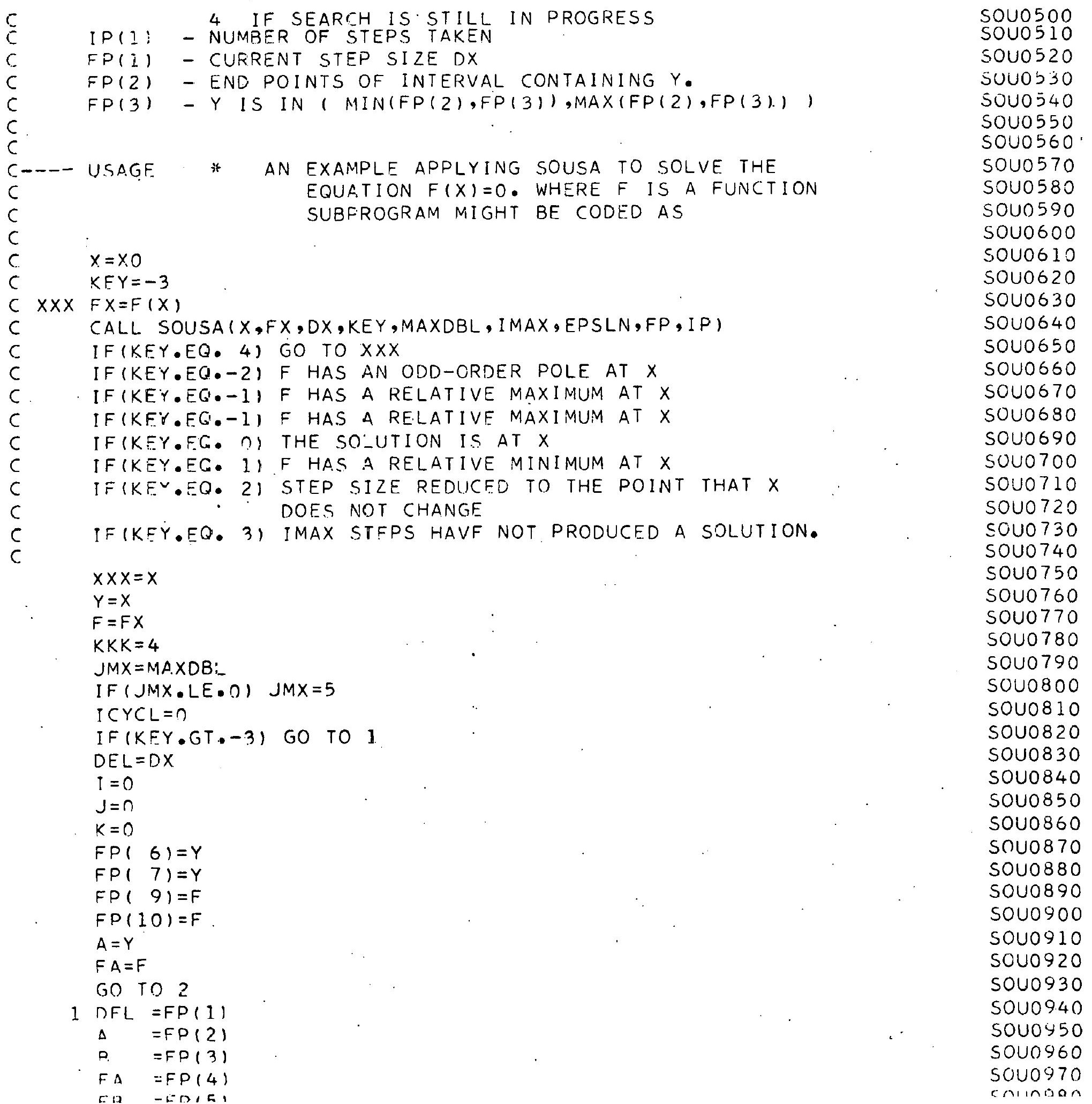




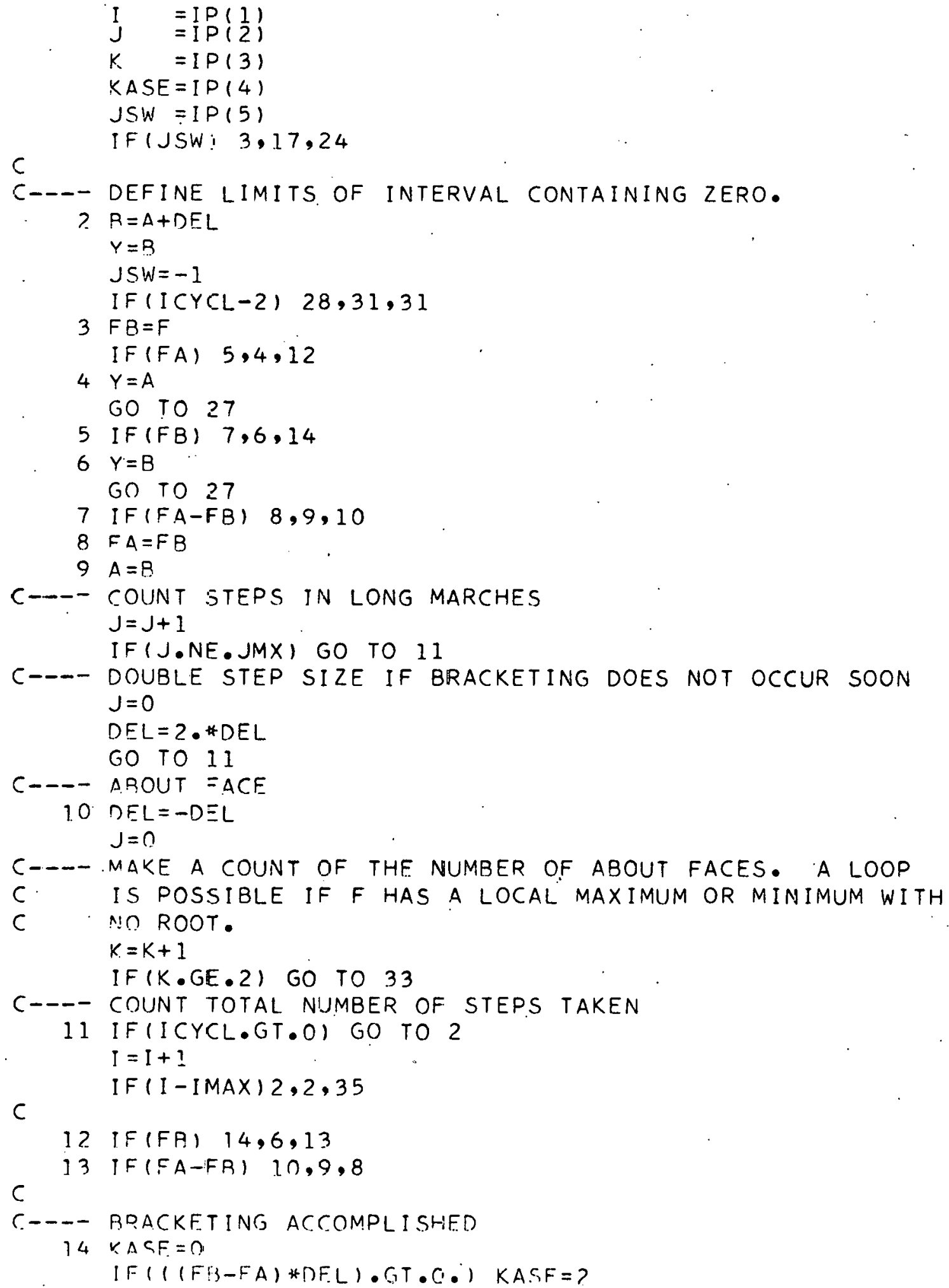


$K A S E=2 * K A S E+1$

C- - - CONVERGING MARCH BEGAN

SOU1510

$17 K A S=K A S F$

$$
\text { I } F \text { (F) } 19,27,18
$$

SOU1520

SOU1530

SOU1540

$18 K \Delta S=K A S+1$

19 Gก TO $(20,21,21,20,21,20,20,21)$, KAS

SOU1550

SOU1560

$20 \quad A=Y$

GO TO 22

$21 B=Y$

C-D- DOUBLE TIME

$22 D F L=D E L / 2$ $Y=A+D E L$

IF(Y.EQ.A ) GO TO 39

IF (Y.EQ.0.) GO TO 23

c

IF $(A R S(D E L / Y)-E P S L N) \quad 27,27,31$

SOU1570

SOU1580

SOU1590

SOU1600

SOU1610

SOU1620

SOU1630

SOU1640

SOU1650

SOU1660

SOU1670

SOU1680

SOU1690

SOU1700

SoU1710

SOU1720

SOU1730

SOU1740

SOU1750

SOU1760

SOU1770

SOU1780

SOU1790

SOU1 800

SOU1810

SOU1820

SOU1830

SOU1840

SOU1850

SOU1860

SOU1 870

SOU1880

SOU1890

SOU1900

Soul910

SOU1920

SOU1930

SOU1940

$30 \times X X=Y$

C---- COUNT REPEATED POINTS

5001450 
$1 \quad I P(1)=I$

I $P(3)=K$

$\operatorname{IP}(4)=K A S E$

$T P(5)=J . S W$

$F P(1)=D E L$

$F D(2)=A$

$F P(3)=B$

$F P(4)=F 4$

$F P(5)=F 3$

SOUI 970
SOUI 980

SOU2000

SOU2010

SOU2020

SOU2030

sou2040

SOU20 20

SOU2060

SOU2070

SOU 2080

SOU2090

SOU2100

SOU2110

sou2120

SOU2 130

SOUZi I 40

SOU2 150

sou2160

$50 \cup 2170$

SOU2I 80

SOU2190

SOU2200

SUU2210

sou2220

SOU2230

sou22 240

SOU2250

SOU 2260

SOU2270

GO TC 32

SOU2280-

ᄃND 